\title{
Nanocrystalline Diamond Films: Applications and Advances in Nanomedicine
}

\author{
Ying-Chieh Chen ${ }^{1,2}$, Don-Ching Lee ${ }^{1}$ and Ing-Ming Chiu $1,3,4^{*}$ \\ ${ }^{1}$ Institute of Cellular and System Medicine, National Health Research Institutes, Miaoli, \\ ${ }^{2}$ Center for Biomedical Engineering, Department of Medicine, \\ Brigham and Women's Hospital, Harvard Medical School, Boston, \\ ${ }^{3}$ Department of Life Sciences, National Chung Hsing University, Taichung \\ ${ }^{4}$ Department of Internal Medicine, The Ohio State University, Columbus \\ 1,3Taiwan \\ 2,4USA
}

\section{Introduction}

Biomaterials play essential roles in modern strategies in regenerative medicine and tissue engineering by designable biophysical and biochemical cues that direct cellular behavior and function [1-4]. The guidance provided by biomaterials may improve restoration and function of damaged or nonfunctional tissues both in cell-based therapies, such as those where carriers deliver transplanted cells or matrices induce morphogenesis in bioengineered tissues constructed ex vivo, and in cellular therapies, such as those where materials induce growth and differentiation of cells from healthy residual tissues in situ [3, 5-7].

Stem cells are defined by their ability to self-renew and produce specialized progeny [8,9]. Consequently, they are the most versatile and promising cell source for the regeneration of aged, injured and diseased tissues. According to their developmental status, stem cells can be classified into two categories: embryonic stem cells and adult stem cells. However, despite the remarkable potential clinical applications of each of these stem-cell populations, their use is currently limited. Thus, a major goal is to develop new culture based approaches, using advanced biomaterials, that more closely mimic what the body already does so well, to promote differentiation of pluripotent cells [3].

Nanomedicine, the application of nanotechnology for medical purpose, is emerging as a new interdisciplinary research field, cutting across biology, chemistry, engineering and medicine. It is expected to lead major advances in disease detection, diagnosis, treatment and further to replacement of damaged tissues and organs. Over the past two decades, there have been significant advances in disease diagnostics, drug delivery, stem cell therapy and tissue engineering. In parallel, nanotechnology has shown great potential for the creation of the next generation of new biomaterials.

Biomaterials that promote regeneration are important in both research and clinical applications [10]. However, current implants have a limited life-expectancy, and younger patients who receive them generally expect to endure revision surgeries to replace worn components. A primary problem with current designs is the generation of wear debris 
particles at the articulating surface that causes local pain and inflammation. Large debris are normally sequestered by fibrous tissue, while small debris are taken up by macrophages and multinucleated giant cells which may release cytokines that result in inflammation. Thus, the proposed solution for the problem caused by wear debris is to develop durable materials for the articulating surfaces that are more wear resistant, which would reduce the generation of debris particles.

Recently, it was shown that diamond particles (NDs), the diamond structure at a nanometer scale (4-5 nm in size), appear to possess high bioactivity at the molecular level, presenting antioxidant and anticarcinogenic properties. Functionalization of NDs with biological molecules, such as peptides, proteins and nucleic acid, has led to practical significance for biomedical applications, covering their use for single particle imaging in cells, drug delivery and protein separation. For instance, carboxylated nanodiamond has been shown as a useful probe for detecting and labeling the interaction of nanoparticles and bio-objects such as cells and bacteria [11], because NDs can be easily functionalized to conjugate with bio-molecules and can emit bright fluorescence without photobleaching [12-15]. Moreover, the ND particles were phagocytosed into cells by macropinocytosis and clathrin-mediated endocytosis pathways during tracking of cells. However, cell growth ability such as cell division and differentiation were not altered after long-term cell culture for 10 days. Together, NDs are non-cytotoxic and with bright fluorescence, thus has served as a versatile tool in biosensing and bioimaging applications $[12,16]$.

Diamond has been one of the most desired and investigated materials in the past years. From an extensive list of superlative properties, the ultra-hardness, the chemical inertness, the high thermal conductivity, and the high optical transparency are just a few examples of its remarkable nature. Applications such as cutting tools, abrasives, structural components, heat sinks, bearings, and optical windows (X-ray, IR, and laser windows) are examples that diamond has a wide-ranging impact in many fields.

\section{Nanodiamond films}

In the late 1980s, polycrystalline diamond films with fine grains were grown for optical coatings [17, 18], wear resistant coatings [19], high-pressure synchrotron X-ray windows [20] and X-ray lithography masks [21]. The first reference to these materials as 'nanocrystalline' was at the Workshop on the Science and Technology of Diamond Films in 1990 [17]. Most of these materials would now be classified as forms of nanocrystalline diamond (NCD) and further characterized the presence of large intrinsic stress and non-diamond phases in these material [22-25]. These NCD materials were all grown in hydrogen-rich chemical vapour deposition (CVD) environments, with typically less than $2 \%$ methane (or hydrocarbon) in hydrogen as reactants, exhibiting clusters (cauliflower morphologies), limited surface smoothness, high compressive stress, delamination, and high content of non-diamond phase. NCD was deposited on Si or other substrates which had been 'treated' or 'seeded' to increase the diamond nucleation density [26, 27]. This wet seeding process was in solution containing diamond powder for ultrasonication to create necessary nucleation sites and the process was varied among labs and individuals [28, 29]. By controlling nucleation density and growth conditions, grain sizes were usually $5-150 \mathrm{~nm}$ for films less than several $\mu \mathrm{m}$ thick. In 1994, Gruen and coworkers [30-32] developed the growth of nanocrystalline diamond films by CVD under hydrogen-poor and carbon-containing argon gas plasmas conditions. In 1999 [33], this new material was reviewed under the label of 'Nanocrystalline 
Diamond Films'. In 2001 [34], the label ultra-nanocrystalline diamond films (UNCD) came to be applied to these materials in order to distinguish them from the more traditional NCD films discussed above [35]. The nanocrystallinity is the result of new growth and nucleation mechanisms, which involve the insertion of $\mathrm{C}_{2}$, carbon dimer, into carbon-carbon and carbon-hydrogen bonds, resulting in heterogeneous nucleation rates on the order $10^{10} \mathrm{~cm}^{2} \mathrm{~s}^{-1}$ $[26,29]$. Detailed investigations using synchrotron-based, near-edge $X$-ray absorption finestructure spectroscopy (NEXAFS) showed that UNCD films grown using this seeding approach and growth chemistry are of very high quality, with greater than $99 \% s p^{3}$ bonding [33]. The UNCD films, a form of NCD, has led to applications in micro-electromechanical systems (MEMS) and nano-electromechanical systems (NEMS) [36-38], corrosion resistance [39], biocompatible coatings [40-42], and biosensors [16, 43, 44].

Diamond coatings with nanosized crystallites, NCD, present a great potential in biomedicine and biotechnology. NCD combines surface smoothness with high corrosion resistance and biotolerance, which are ideal features for applications in medicine onto surgical tools and medical implants. For example, joint implants coated with NCD can take benefit of its protective character. The NCD coating acts as a selective protective barrier between the implant and the human environment, preventing the release of metallic ions into the body. NCD presents the highest resistance to bacterial colonization when compared to medical steel and titanium [45]. This property is very important since infection due to microbial colonization of the implant surface may lead to implant rejection. In addition, the high wear resistance and the low coefficient of friction of NCD allow the reduction of the amount of wear debris generated during the joint functioning, thus increasing the life of the prosthesis [46]. Further, the residues formed due to wear in this case are diamond particles, which are completely harmless, initiating little or no adverse reactions from human monocytes and polymorphonuclear leukocytes [47-49]. NCD is also included in this recent group of materials and can be used as a template for the immobilization of active molecules for biological applications or for biosensor applications [44, 50-52]. One example is the functionalization of NCD surface with bone morphogenetic protein-2 (BMP-2) creating a biomimetic coating that results in improved osseointegration, which is a powerful strategy in tissue engineering as well as in bone tissue regeneration [53]. The NCD surface can also be modified with the linking of antibody, human IgG, which provide biomolecular recognition capability and specificity characteristics, proving a biologically sensitive fieldeffect transistor (Bio-FET) [44].

This paper offers a review of present knowledge of the synthesis and characterization, cell behavior, focused on in vitro adhesion, proliferation and differentiation on nanodiamond films. The aim is to highlight nanodiamond films as new generation biomaterials for improving the future development on clinical transplantation and tissue engineering.

\section{Surface modifications}

Cellular adhesion is of fundamental importance in many biological processes as the adhered cells will sense, interpret, integrate, and then respond to the extracellular signals. Chemical and physical signals from the substrate such as surface energy, topography, electrostatic charge, and wettability play a vital role in stimulating cell adhesion and influencing cell growth behavior. The cellular adhesion properties of as-grown diamond surfaces or functionalized diamond surfaces have been studied recently. The as-grown diamond films were characterized as hydrophobic surfaces with abundance of $\mathrm{C}-\mathrm{C}$ and $\mathrm{C}-\mathrm{H}$ bonds [54]. 
The functionalized surface properties of diamond can be made hydrophobic or hydrophilic with hydrogen or oxygen termination, respectively, which have implications for cellular adhesion. The methods of surface modifications are summarized as following:

1. Hydrogen termination (hydrophobic surface):

2. Diamond films were treated in pure hydrogen plasma treatment at 300-800 $\mathrm{W}$ in the microwave plasma CVD system at 5 mTorr for 2-15 min. All freshly prepared hydrogen-terminated diamond samples were used immediately for cell culture.[55-58]

3. Oxygen termination (hydrophilic surface):

a. Diamond samples were exposed to UV irradiation $(18 \mathrm{~W}, 254 \mathrm{~nm})$ for $18 \mathrm{~h}$ in air. After UV functionalization, the samples were rinsed with ultrapure water, tetrahydrofuran, and finally with hexane.[55]

b. Diamond films were exposed to pure oxygen plasma CVD system at $800 \mathrm{~W}$ at 5 mTorr for 10-15 min.[56, 58]

c. Diamond films were oxidized in concentrated $\mathrm{HNO}_{3}$ at $60-70^{\circ} \mathrm{C}$ for 24 hours. This oxidation reaction transformed the face of the film from hydrophobic to hydrophilic surface by adding carboxylate groups to the films. [59, 60]

4. Bio-molecular conjugation [61-64]

\section{Nanodiamond-cell interaction: biological performance and response}

Cell adhesion is involved in various natural phenomena such as embryogenesis, maintenance of tissue structure, wound healing, immune response, and tissue integration of biomaterial. The biocompatibility of biomaterials is very closely related to cell behavior on contact with them and particularly to cell adhesion to their surface. Surface characteristics of materials, such as their topography, chemistry, or surface energy, play an essential part in cell adhesion on biomaterials. Thus attachment, adhesion and spreading belong to the first phase of cell/material interactions and the quality of this phase will influence the cell's capacity to proliferate or to differentiate itself on contact with the implant. Material/cell interaction depends on the surface aspects of materials which may be described according to their wettability, topography, chemistry and surface energy. These surface characteristics determine how and what kinds of biological molecules will adhere to the surface and more particularly determine the orientation of adhered molecules, and also finally determine the cell behavior while in contact $[3,8,65]$. As previously shown, cells in contact with a surface will firstly attach, adhere and then spread. This first phase depends on specific adhesion proteins such as integrin and cadherin as demonstrated by Chen et al [66]. Thereafter, the quality of this adhesion will influence their morphology, and their capacity for proliferation and differentiation. Early in vitro biocompatibility and cytocompatibility studies focused on the morphology and growth capacity of cells on nanodiamond films with various chemical compositions and topographies [15, 53, 56, 58, 67, 68]. Recently, it was found that nanodiamond films further determine the differentiating stage in stem cells, which expands other possibilities for nanodiamond films into organ repair and tissue engineering.

\subsection{Biocompatibility tests: morphological aspect and growth capacity of cells on nanodiamond films}

NCD films possess numerous valuable physical, chemical and mechanical properties, making NCD an excellent material for implantable biomedical devices. There is still one 
very important property required for biomaterials, i.e., biocompatibility. The biocompatibility of a material is determined by in vitro and in vivo tests, involving the interaction of the material with cells.

In vitro studies of biocompatibility of UNCD coatings, produced by MPECVD using $\mathrm{Ar} / \mathrm{CH}_{4}$ as reactive gas, were carried out by Shi et al. [69]. They grew mouse embryonic fibroblasts (MEFs) on UNCD films up to 4 days and found that UNCD film coated substrates can dramatically promote the growth of MEFs, while the quartz substrates inhibit cell attachment. On growing human cervical carcinoma cell line (HeLa), neuronal cell line (PC12) and osteoblastic cells (MC3T3) on UNCD films, no toxicological effects on the cells in culture were observed. It was noted that maximum cell attachment, cell spreading and nuclear coverage were observed on UNCD films compared to two commonly used materials in MEMS platinum and silicon substrates [70]. Amaral et al performed bone marrow cell culture tests on NCD films, prepared by using a hot-filament chemical vapor deposition (HFCVD) technique in Ar- $\mathrm{CH}_{4}-\mathrm{H}_{2}$ gas mixtures, to observe its effects on cellular reaction, osteoblast, and osteoblast activity [71]. The nanometric feature of NCD resulted in increased bone cell proliferation and minimized activity of osteoclast-like cells. Following previous study, Amaral and coworkers cultured primary human gingival fibroblast cell cultures on NCD films for 21 days and no damage to the cells was observed. On performing the cytotoxicity tests using a standard cell line, it was found out that NCD films promotes cell attachment and normal cell growth rates [72]. Several other studies were made on the morphological behavior of mesenchymal stem cells on NCD coating prepared by MPECVD method in hydrogen-rich gas mixtures, which revealed good surface biocompatibility of the coatings [58]. Their investigations indicated that NCD coatings were biocompatible to not only cell lines, but also primary stem cells.

All these in vitro studies showed that NCD films tended to promote the growth and adhesion of cells without any toxicological effect. There are other applications where it is desirable that there should not be any cell attachment to a surface, for example, in case of catheters and temporary implants. After getting a primary indication of the biocompatibility of NCD films through in vitro tests, several in vivo studies were initiated by implants with NCD coating in laboratory animals. An attempt was made to study the osseous healing at the implant sites by inserting implants into 4-year-old female sheep calvaria for 3 days, 1 week and 4 weeks intervals. It was observed that implant surfaces coating with NCD films and then conjugating with BMP-2 enhanced osseointegration in vivo. After implanting NCD coated implants in transplantation sites of sheep for different time periods, it has been observed that the NCD-coated implants did not show any significant toxicological effect and are well tolerated in the sheep body. Results further suggest that this technical advancement can be readily applied in clinical therapies with regard to bone healing, since primary human mesenchymal stromal cells strongly activated the expression of osteogenic markers when being cultivated on NCD absorbed with physiological amounts of BMP-2 [73].

The above in vitro and in vivo studies indicated the biocompatibility of NCD films prepared by a variety of techniques. The general finding so far is that control of cell adhesion and proliferation on NCD can be achieved by altering NCD surface chemistry and surface topography and wettability, probably due to the correlation between these surface properties and the adsorption of endogenous proteins that regulate cell behavior. Adsorbed proteins can be detected on biomaterials within seconds of exposure to the blood, and a monolayer of adsorbed proteins forms in seconds to minutes. Fibronectin, vitronectin and laminin are pro-adhesive proteins, with relatively high concentration in blood, that are 
recognized by various cellular integrin receptors [74]. It has been observed that fibronectin governs the adhesion and spreading of cells on a material surface [75]. These plasma proteins play an important role in the initial recruitment of cells to the biomaterial surface. The glycoprotein fibronectin consists of multiple specific binding sites and is capable of interacting with a wide variety of other biomaterials, through the formation of fibrilar extracellular matrix or fibrils. So, the specific surface of a biomaterial plays a key role in adsorption of fibronectin or other pro-adhesive proteins and hence better proliferation of cells. The interaction of neural stem cells with UNCD films and the consequent cellular signaling processes are schematized in Figure 1. Some studies revealed that the adhesion and spreading of cells on NCD surfaces is related to the bonding structure present on the surface and the ratio of $s p^{2} / s p^{3}$ [76]. It has also been observed that the microstructure of the NCD films and the kind of treatments seemed to influence the biological effects of cells. However, the correlation between these surface properties (chemistry, topography and wettability) and cell responses is complicated and not clearly understood.

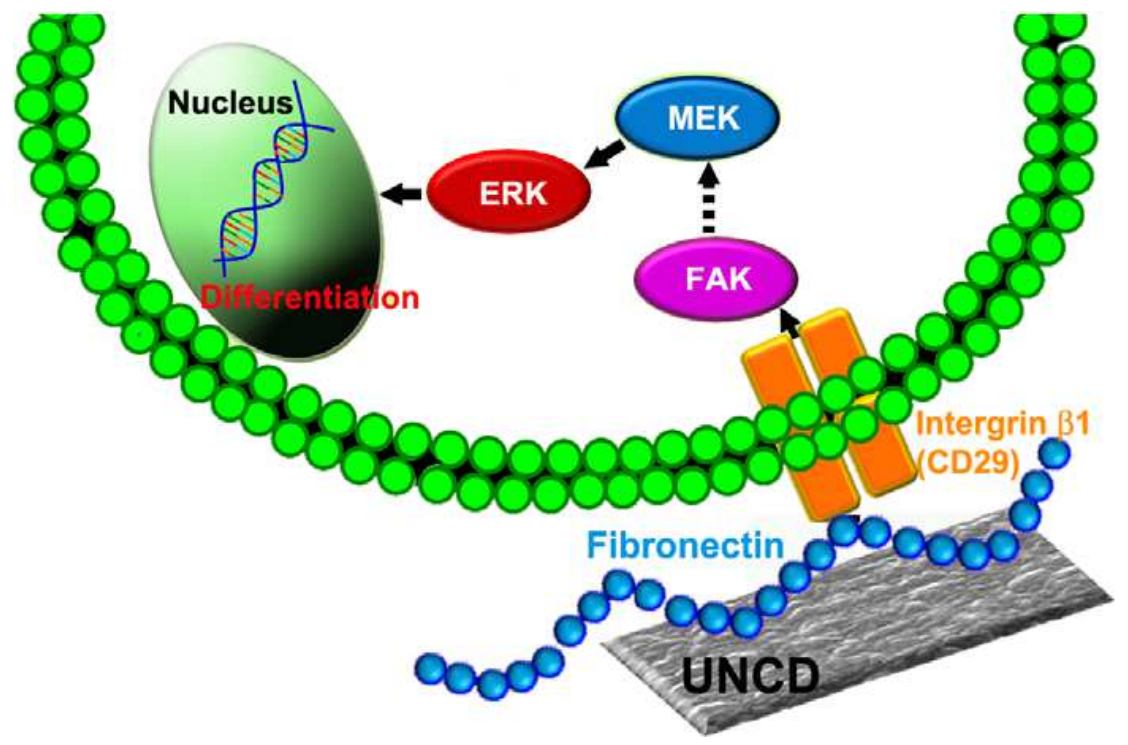

Fig. 1. Schematic drawing summarizes the role of H-UNCD films in mediating differentiation from neural stem cells. Absorbed fibronectin on H-UNCD surface activates integrin $\beta 1$ (CD29), focal adhesion kinase (FAK) and (extracellular signaling kinase) ERK1/2 pathways and, in turn, leads to an ultimate and specification of neuronal differentiation from NSC.

\subsection{Topography effects of nanodiamond films on cells}

The comparison of the behavior of different cell types on nanodiamond films shows that they react differently according to surface smoothness [55, 57, 60, 68, 77, 78]. Scanning electron microscopy (SEM) and immunofluorescence staining examinations of osteoblast on nanodiamond films with various surface roughness (nanometer and micrometer) generally demonstrated that enhanced osteoblast functions (including adhesion, proliferation, 
intracellular protein synthesis, alkaline phosphatase activity and extracellular calcium deposition) on nanocrystalline diamond (RMS $20 \mathrm{~nm}$ ) compared to submicron diamond grain size films and control for all time periods tested up to 21 days [57, 60]. In addition, an SEM study of osteoblast attachment on NCD films explains the topographical impact diamond had on osteoblast functions by showing complex and longer filopodia extensions.

To investigate the adhesion of normal human dermal fibroblast cells grown on NCD films with various surface smoothnesses, atomic force microscopy were performed. The examination demonstrated that cell viability and adhesion force was better on smooth surfaces (UNCD films) compared to micron diamond grain size films, no matter the terminations of diamond films [55]. Although mesenchymal stem cells and nondifferentiated cells adhere similarly on all NCD surfaces with different roughness (20, 270, and $500 \mathrm{~nm}$ ) and control polystyrene, their metabolic activity on NCD surfaces is increased. On the other hand, osteoblasts adhere on NCD significantly more than on polystyrene, and their metabolic activity is decreased on nano/microrough NCD surfaces in contrast to mesenchymal stem cells. These differences could be attributed to the distinct properties of the two cell types in the human body. Alternatively, the different response of osteoblasts could be attributed to the specific surface topography as well as to the biocompatible properties of diamond. [79]. Hence the controlled topographically structured NCD coatings on various substrates is promising for preparation of better implants, which offer faster colonization by specific cells as well as longer-term stability.

\subsection{Surface chemistry effects of nanodiamond films on cells}

The bio-compatibility and resistance to chemical corrosion of diamond may increase lifetime of stents, joints, and other implants in the human body. It is also possible to make a chemical functionalization of diamond surface and create bio-passive or bio-active patterns. Kalbacova et al [80] showed that viability and adhesion of human osteoblasts (SAOS-2) cultured on NCD films are predominantly determined by NCD surface termination. Increasing surface nano-roughness plays a secondary yet positive role. Hydrophilic surface of NCD films (O-terminated surface) provides good conditions for osteoblast adhesion and spreading and consequently on their viability (metabolic activity and proliferation). It was shown that hydrophobic H-terminated diamond surfaces are less favorable for osteoblastlike cell adhesion and growth than hydrophilic O-terminated surfaces [80, 81]. This is in agreement with observations on other materials and cells, such as Ti6Al4V titanium alloy $[82,83]$ and human dermal fibroblast [55]. In addition to cells lines, different kinds of stem cells have also been studied and the results show difference on cell lines and stem cells. Chen et al [56] cultured neural stem cells on different functionalized diamond films in low serum and without any differentiation factors to investigate the biological effects on NSCs. We found that H-terminated UNCD films spontaneously induced cell proliferation and neuronal differentiation and O-terminated UNCD films were also shown to further improve neural differentiation, with a preference to differentiate into oligodendrocytes. Clem [58] reported that H-terminated ultra-smooth nanostructured diamond surfaces supported robust adhesion and survival of mesenchymal stem cells, while oxygen (O)- and fluorine (F)-terminated surfaces resisted cell adhesion. Thalhammer [84] used four different materials (glass, PCD, NCD and Si) coated with monolayers nanodiamonds and displayed promising similarity to the protein-coated materials regarding neuronal cell attachment, 


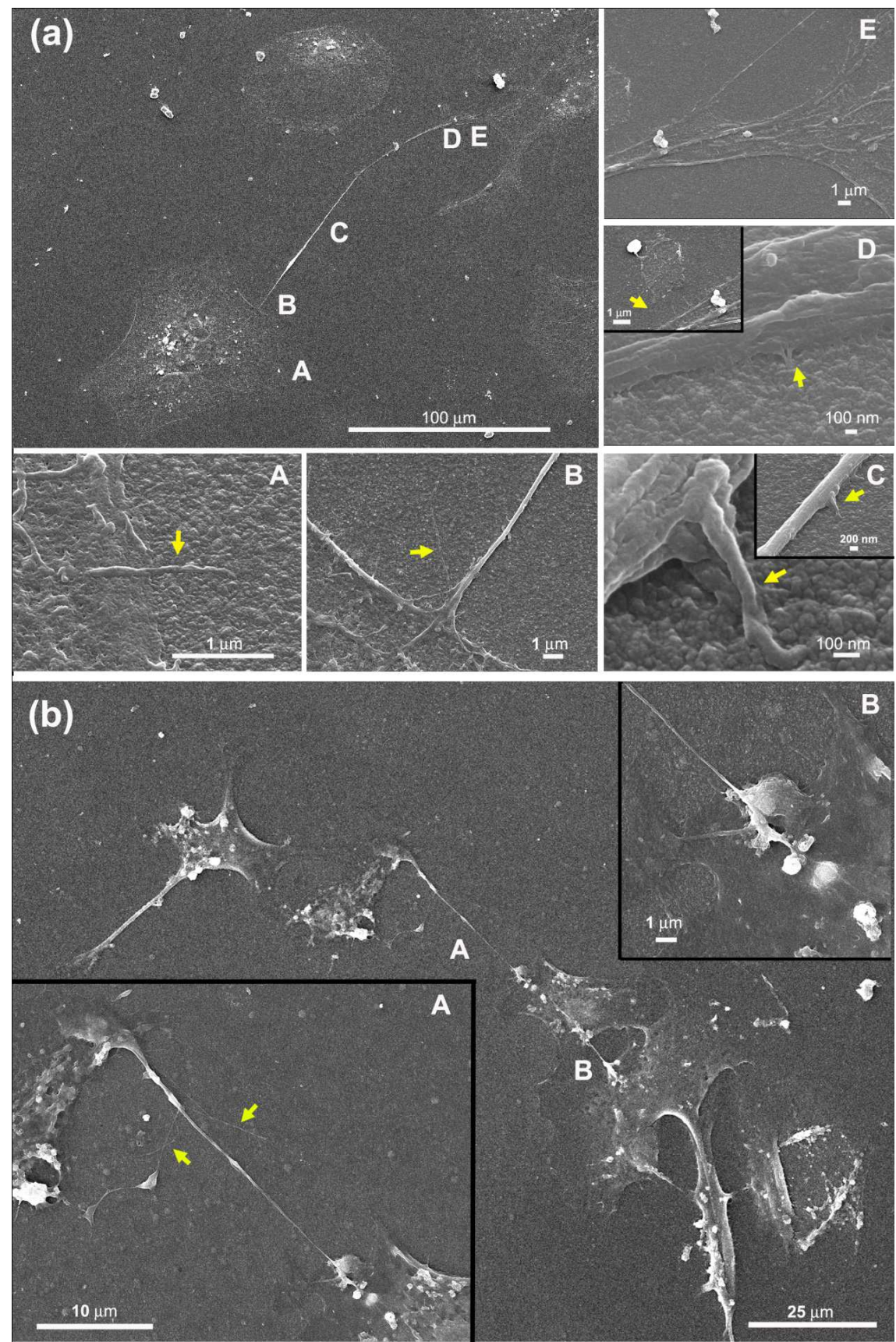

Fig. 2. Scanning electron photomicrographs of neural stem cells cultured on H-UNCD films in regular medium without any differentiating reagents for seven days. Higher 
magnification scanning electron microscopy was performed to enlarge different areas (A-E) in graph (a) and (A-B) in graph (b). Yellow arrows show the filopodia at higher magnifications.

neurite outgrowth and functional network formation. Importantly, the neurons were able to grow in direct contact with the NCD-coated material and could be easily maintained in culture for an extended period, equal to those on protein-coated substrates. To further investigate the interaction of cell to NCD film, Chen et al observed the morphology of cells cultured in H-terminated UNCD films and revealed that there were filopodia/nanodiamond interactions (Figure 2). Thus, NCD layering might prove a valuable material for implants on a wide range of substrates. These indicate that diamond films can be easily modified to either promote or prevent cell/biomaterial interactions. This is an interesting feature for tissue engineering and bio-electronics. A question remained though to what kinds of mechanism and key points to affect the degree of the cell adhesion and selectivity.

\section{Molecular mechanisms of signaling transduction from UNCD films to nuclei}

Cells do not interact with a naked material either in vitro or in vivo. At the beginning step, the material is conditioned by the biological fluid components. This is a complex process strongly dependent on the cell culture conditions including the underlying substrate and mediating medium/proteins. Surface energy may influence protein adsorption and the structural rearrangement of the proteins on positively and negatively charged substrates (hydrophilic/hydrophobic surface). Protein from serum containing media adsorbed on surfaces forming multiple molecular layers. Hydrophobic H-terminated surfaces were found less favorable for osteoblastic cell adhesion, spreading and viability than hydrophilic O-terminated surfaces [5]. Recently, it was shown that microscopic (30-200 $\mu \mathrm{m})$ patterns of $\mathrm{H}$ - and O-terminated surface can lead to a selective adhesion and arrangement of osteoblasts [85]. This effect also works on human periodontal ligament fibroblast and human cervical carcinoma (HeLa) cells [85-87]. The differential adsorption of "serum proteins" on the negative or positive charged regions from medium with fetal bovine serum (FBS) was studied. It was proposed that the selectivity is due to the serum proteins, which are adsorbed in about the same monolayer thickness $(2-4 \mathrm{~nm})$ on both $\mathrm{H}$ and O-diamond surfaces, but in different composition and conformations of proteins [88]. When osteoblasts were placed on the diamond surface in McCoy's 5A medium without FBS, cell attachment on $\mathrm{H} / \mathrm{O}-$ patterned diamond surfaces was not selective $[85,89]$. This excluded a direct effect of diamond $\mathrm{C}-\mathrm{H}$ and $\mathrm{C}-\mathrm{O}$ surface dipoles on the cell selectivity. FBS adsorption to diamond proceeds in two stages. Formation of monolayer thickness $(2-4 \mathrm{~nm})$ FBS layer on both Hand O-diamond was observed within short period of time $(<18 \mathrm{~h})[86,88]$. AFM nanoshaving showed that this primary FBS layer is less adhesive to H-diamond than to Odiamond. After long time adsorption (6 days), formation of a thick FBS layer was observed on H-diamond $(\sim 35 \mathrm{~nm})$ than on O-diamond $(\sim 17 \mathrm{~nm})$ [86]. Moreover, it is clear that not only the nature of adsorbed biological molecules but also their conformation and composition will influence consequent cell adhesion. Changes in conformation of preadsorbed specific proteins, fibronectin, (not bovine serum albumin or vitronectin, which is abundant in FBS) were observed. These would affected cell binding domain conformations and then affect the affinity with its cell surface receptor $[58,86]$. 
Osteoblast adhesion on materials may also be considered in relation to the expression of the various adhesion proteins and cell receptors. Numerous studies using immunefluorescent staining have shown the presence of vinculin and pY397 focal adhesion kinase (FAK) in cultured human osteoblasts on nanostructured diamond films [60, 78, 79]. The osteoblasts adhered on ultra nano-cones and nano-cones, showing large focal adhesions and relatively strong activation of FAK, are thus more predestined for successful colonization of the entire environment [60, 78]. Hamilton [90] suggested that osteoblast response to substrates with specific topographical features requires FAK-Y397-Src-Y416 complexes for ERK1/2 phosphorylation. Yet on smooth surfaces, Src-independent routes of ERK1/2 activation are present, which finally induce the differentiation of osteoblast further to promote bone formation. The same cell signaling pathway has been studied on other materials, such as titanium alloys [83]. According to published data, the contact of cell to fibronectin could be
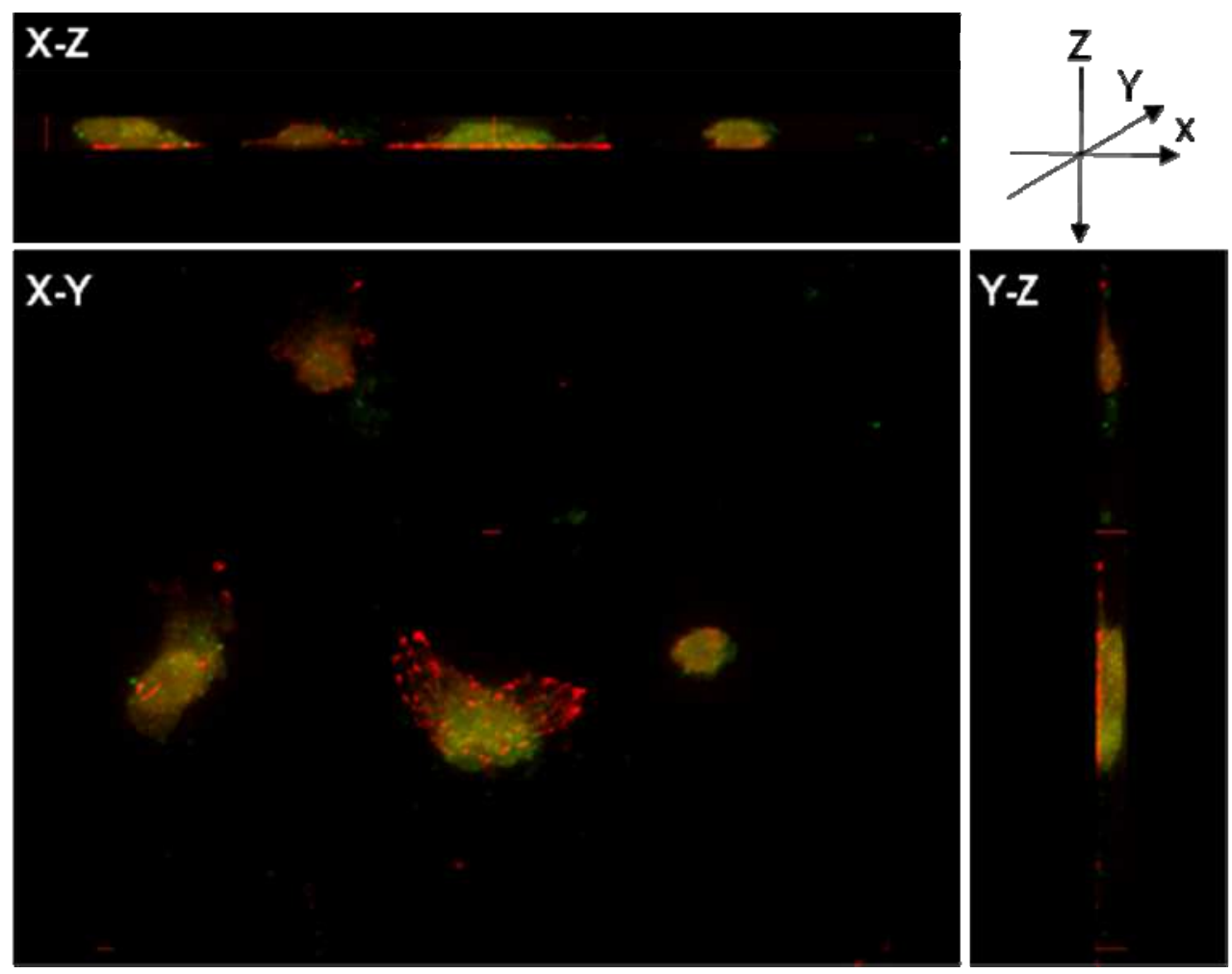

Fig. 3. The confocal immunofluorescence image of neural stem cells grown on the H-UNCD film in the regular medium without any differentiating reagents for 8 hours of culture. Alexafluor 594 labeled phospho-FAK (Red) and DyLight 488 labeled phospho-ERK (Green). The phospho-FAK and phospho-ERK were detected in the cells simultaneously and localized to their proper subcellular positions. In the quadrant of X-Z and Y-Z stacking images, phospho-FAK was observed in basal cell membrane adherent to H-UNCD films, while phosphor-ERK was shown assembled in the cell body. 
mediated by integrin $\beta 1[91,92]$. Integrins are transmembrane protein family and composed of $\alpha$ and $\beta$ subunits as heterodimer. Functions of integrins were involved in the regulation of proliferation, survival, migration and differentiation. The high level of integrin $\beta 1$ expression has been used to enrich human epidermal and rodent neural stem cells from more restricted progenitor populations [58, 92]. Moreover, Chen et al [66] showed that increased levels of neuronal differentiation in neural stem cells grown on H-UNCD surfaces are due to absorbance of fibronectin from medium to H-terminated UNCD films, resulting in integrin $\beta 1$-FAK-ERK1/ 2 signaling (Figure 3) in conditions of low serum-growth factors and free of differentiating reagents.

\begin{tabular}{|c|c|c|c|}
\hline Number & Function & gi number & Name \\
\hline 1 & $\begin{array}{c}\text { Extracellular } \\
\text { matrix }\end{array}$ & 224863 & Fibronectin \\
\hline 2 & \multirow{10}{*}{ Blood } & 78099200 & Hemoglobin subunit epsilon \\
\hline 3 & & 126022898 & Hemoglobin alpha subunit 1 \\
\hline 4 & & 203283896 & Apolipoprotein A-I preproprotein \\
\hline 5 & & 3915607 & Apolipoprotein A-I \\
\hline 6 & & 77735387 & Fetuin B \\
\hline 7 & & 166159174 & $\begin{array}{l}\text { Angiotensinogen (serpin peptidase inhibitor, clade A, } \\
\text { member } 8 \text { ) }\end{array}$ \\
\hline 8 & & 95147674 & Complement factor B \\
\hline 9 & & 2501351 & Transferrin \\
\hline 10 & & 27807209 & Alpha-2-macroglobulin \\
\hline 11 & & 78369364 & $\begin{array}{l}\text { Group-specific component (vitamin D binding } \\
\text { protein) }\end{array}$ \\
\hline 12 & \multirow{5}{*}{ Epithelium } & 16303309 & Type II keratin 5 \\
\hline 13 & & 148747492 & Keratin 2 \\
\hline 14 & & 73996312 & $\begin{array}{l}\text { Similar to Keratin, type II cytoskeletal } 5 \text { (Cytokeratin } \\
\text { 5) ( } 58 \mathrm{kDa} \text { cytokeratin) isoform } 3\end{array}$ \\
\hline 15 & & 9910294 & Keratin 71 \\
\hline 16 & & 4159806 & Type II keratin subunit protein \\
\hline 17 & Cytoskeleton & 28336 & Mutant beta-actin \\
\hline 18 & \multirow{3}{*}{ Others } & 27806907 & Clusterin \\
\hline 19 & & 2232299 & IgM heavy chain constant region \\
\hline 20 & & 27806809 & Regucalcin \\
\hline
\end{tabular}

Table 1. Differential protein expression profile identified by LC-MS/MS, showing proteins preferentially absorbed on H-UNCD films, but not on Petri dish polystyrene surface.

\section{Proteomic analysis of proteins that are adsorbed to UNCD films by using LC-MS/MS}

We showed that the abundant fibronectin adsorbed onto the H-UNCD film formed locally dense and conformed layer that allows for the pro-adhesive motifs to be accessible by integrins and further activates the whole signaling pathway [66]. To further investigate what other serum proteins might be bound to UNCD films, we performed proteomic analysis, 
using LC-MS/MS on serum proteins that are adsorbed to H-UNCD films. We demonstrated that H-UNCD films could adsorb proteins from culture medium more efficient than Petri dish's polystyrene surface could (Table 1). These proteins included not only fibronectin but also proteins that are known to be present in blood, epithelium, cytoskeleton, and others. It would be of interest to further explore the roles of these proteins in shaping the UNCD-cell interaction and the ultimate differentiation into desired cell types.

\section{Conclusion}

Highly intense research on biocompatibility of NCD films showed that it is a promising material for biomedical applications. NCD films possess easy surface functionalization and nano-topography, offering favorable condition for the growth of fibroblasts, osteoblasts and stem cells without inflammatory response and cytotoxicity. From published in vitro studies, NCD films elicited an improved proliferation and differentiation capacity for human osteoblasts and neural stem cells, compared to conventional polystyrene Petri dishes. The relevant mechanism of cellular signaling transduction has been investigated and shown to act through fibronectin-integrin-FAK-ERK pathway. These results suggest the potential usage of NCD films as novel medical devices and implants such as a coating for joint implant and nerve repair in tissue engineering. The delamination and corrosion of the NCD films during its long-term use in medical implants are to be carefully considered for its future biomedical applications. We performed proteomic analysis, using LC-MS/MS, to identify proteins that are adsorbed to UNCD films. We demonstrated proteins such as fibronectin, transferrin, and several keratin proteins that could be adsorbed more efficiently onto UNCD films than to Petri dish's polystyrene surface. It would be of interest to further explore the roles of these proteins in shaping the UNCD-cell interaction and the subsequent differentiation into desired cell types. Finally, more systematic studies in vivo are now warranted to confirm its use in biomedical devices for commercial applications.

\section{References}

[1] Peppas NA, Langer R. New Challenges in Biomaterials. Science 1994 Mar;263(5154):1715-1720.

[2] Hubbell JA. Biomaterials in Tissue Engineering. Bio-Technology 1995 Jun;13(6):565-576.

[3] Lutolf MP, Hubbell JA. Synthetic biomaterials as instructive extracellular microenvironments for morphogenesis in tissue engineering. Nat Biotechnol 2005 Jan;23(1):47-55.

[4] Langer R, Tirrell DA. Designing materials for biology and medicine. Nature 2004 Apr;428(6982):487-492.

[5] Discher DE, Mooney DJ, Zandstra PW. Growth Factors, Matrices, and Forces Combine and Control Stem Cells. Science 2009 Jun;324(5935):1673-1677.

[6] Chai C, Leong KW. Biomaterials approach to expand and direct differentiation of stem cells. Mol Ther 2007 Mar;15(3):467-480.

[7] Hwang NS, Varghese S, Elisseeff J. Controlled differentiation of stem cells. Adv Drug Deliv Rev 2008 Jan;60(2):199-214.

[8] Lutolf MP, Gilbert PM, Blau HM. Designing materials to direct stem-cell fate. Nature 2009 Nov;462(7272):433-441. 
[9] Morrison SJ, Spradling AC. Stem cells and niches: Mechanisms that promote stem cell maintenance throughout life. Cell 2008 Feb;132(4):598-611.

[10] Guilak F, Cohen DM, Estes BT, Gimble JM, Liedtke W, Chen CS. Control of Stem Cell Fate by Physical Interactions with the Extracellular Matrix. Cell Stem Cell 2009 Jul;5(1):17-26.

[11] Chao JI, Perevedentseva E, Chung PH, Liu KK, Cheng CY, Chang CC, et al. Nanometersized diamond particle as a probe for biolabeling. Biophysical Journal 2007 Sep;93(6):2199-2208.

[12] Liu KK, Wang CC, Cheng CL, Chao JI. Endocytic carboxylated nanodiamond for the labeling and tracking of cell division and differentiation in cancer and stem cells. Biomaterials 2009 Sep;30(26):4249-4259.

[13] Vaijayanthimala V, Tzeng YK, Chang HC, Li CL. The biocompatibility of fluorescent nanodiamonds and their mechanism of cellular uptake. Nanotechnology 2009 Oct;20(42):9.

[14] Ho DA. Beyond the Sparkle: The Impact of Nanodiamonds as Biolabeling and Therapeutic Agents. Acs Nano 2009 Dec;3(12):3825-3829.

[15] Schrand AM, Hens SAC, Shenderova OA. Nanodiamond Particles: Properties and Perspectives for Bioapplications. Critical Reviews in Solid State and Materials Sciences 2009;34(1-2):18-74.

[16] Chan HY, Aslam DM, Wiler JA, Casey B. A Novel Diamond Microprobe for NeuroChemical and -Electrical Recording in Neural Prosthesis. Journal of Microelectromechanical Systems 2009 Jun;18(3):511-521.

[17] Ong TP, Chiou WA, Chen FR, Chang RPH. Preparation of Nanocrystalline Diamond Films for Optical Coating Applications Using a Pulsed Microwave Plasma Cvd Method. Carbon 1990;28(6):799-799.

[18] Ong TP, Chang RPH. Low-Temperature Deposition of Diamond Films for Optical Coatings. Applied Physics Letters 1989 Nov;55(20):2063-2065.

[19] Fan WD, Wu H, Jagannadham K, Goral BC. Wear-Resistant Diamond Coatings on Alumina. Surface \& Coatings Technology 1995 May;72(1-2):78-87.

[20] Kato M, Fujisawa T. High-pressure solution X-ray scattering of protein using a hydrostatic cell with diamond windows. Journal of Synchrotron Radiation 1998 Sep;5:1282-1286.

[21] Ravet MF, Rousseaux F. Status of diamond as membrane material for X-ray lithography masks. Diamond and Related Materials 1996 May;5(6-8):812-818.

[22] Sharda T, Umeno M, Soga T, Jimbo T. Strong adhesion in nanocrystalline diamond films on silicon substrates. Journal of Applied Physics 2001 May;89(9):4874-4878.

[23] Lifshitz Y, Meng XM, Lee ST, Akhveldiany R, Hoffman A. Visualization of diamond nucleation and growth from energetic species. Physical Review Letters 2004 Jul;93(5):4.

[24] Lee YC, Lin SJ, Chia CT, Cheng HF, Lin IN. Effect of processing parameters on the nucleation behavior of nano-crystalline diamond film. Diamond and Related Materials 2005 Mar-Jul;14(3-7):296-301.

[25] Berry BS, Pritchet WC, Cuomo JJ, Guarnieri CR, Whitehair SJ. INTERNAL-STRESS AND ELASTICITY OF SYNTHETIC DIAMOND FILMS. Applied Physics Letters $1990 \mathrm{Jul} ; 57(3): 302-303$. 
[26] Liu YK, Tso PL, Lin IN, Tzeng Y, Chen YC. Comparative study of nucleation processes for the growth of nanocrystalline diamond. Diamond and Related Materials 2006 Feb-Mar;15(2-3):234-238.

[27] Lee ST, Lin ZD, Jiang X. CVD diamond films: nucleation and growth. Mater Sci Eng RRep 1999 Jul;25(4):123-154.

[28] Sumant AV, Gilbert P, Grierson DS, Konicek AR, Abrecht M, Butler JE, et al. Surface composition, bonding, and morphology in the nucleation and growth of ultra-thin, high quality nanocrystalline diamond films. Diam Relat Mat 2007 Apr-Jul;16(47):718-724.

[29] Naguib NN, Elam JW, Birrell J, Wang J, Grierson DS, Kabius B, et al. Enhanced nucleation, smoothness and conformality of ultrananocrystalline diamond (UNCD) ultrathin films via tungsten interlayers. Chem Phys Lett 2006 Oct;430(4-6):345-350.

[30] Gruen D, Krauss A. Buckyball precursors produce ultra-smooth diamond films. R\&D Magazine 1997 Apr;39(5):57-\&.

[31] Gruen DM, Liu SZ, Krauss AR, Luo JS, Pan XZ. FULLERENES AS PRECURSORS FOR DIAMOND FILM GROWTH WITHOUT HYDROGEN OR OXYGEN ADDITIONS. Applied Physics Letters 1994 Mar;64(12):1502-1504.

[32] Gruen DM, Pan XZ, Krauss AR, Liu SZ, Luo JS, Foster CM. DEPOSITION AND CHARACTERIZATION OF NANOCRYSTALLINE DIAMOND FILMS. Journal of Vacuum Science \& Technology a-Vacuum Surfaces and Films 1994 JulAug;12(4):1491-1495.

[33] Gruen DM. Nanocrystalline diamond films. Annual Review of Materials Science 1999;29:211-259.

[34] Gruen DM. Ultrananocrystalline diamond in the laboratory and the cosmos. Mrs Bulletin 2001 Oct;26(10):771-776.

[35] Butler JE, Sumant AV. The CVD of nanodiamond materials. Chem Vapor Depos 2008 Jul-Aug;14(7-8):145-160.

[36] Hutchinson AB, Truitt PA, Schwab KC, Sekaric L, Parpia JM, Craighead HG, et al. Dissipation in nanocrystalline-diamond nanomechanical resonators. Applied Physics Letters 2004 Feb;84(6):972-974.

[37] Sekaric L, Parpia JM, Craighead HG, Feygelson T, Houston BH, Butler JE. Nanomechanical resonant structures in nanocrystalline diamond. Applied Physics Letters 2002 Dec;81(23):4455-4457.

[38] Zhang JC, Zimmer JW, Howe RT, Maboudian R. Characterization of boron-doped micro- and nanocrystalline diamond films deposited by wafer-scale hot filament chemical vapor deposition for MEMS applications. Diamond and Related Materials 2008 Jan;17(1):23-28.

[39] Lee CK. Effects of hydrogen and oxygen on the electrochemical corrosion and wearcorrosion behavior of diamond films deposited by hot filament chemical vapor deposition. Applied Surface Science 2008 Apr;254(13):4111-4117.

[40] Yang WS, Auciello O, Butler JE, Cai W, Carlisle JA, Gerbi J, et al. DNA-modified nanocrystalline diamond thin-films as stable, biologically active substrates. Nature Materials 2002 Dec;1(4):253-257.

[41] Yang WS, Auciello O, Butler JE, Cai W, Carlisle JA, Gerbi J, et al. DNA-modified nanocrystalline diamond thin-films as stable, biologically active substrates (vol 1, pg 253, 2002). Nature Materials 2003 Jan;2(1):63-63. 
[42] Yang WS, Butler JE, Russell JN, Hamers RJ. Interfacial electrical properties of DNAmodified diamond thin films: Intrinsic response and hybridization-induced field effects. Langmuir 2004 Aug;20(16):6778-6787.

[43] Ariano P, Lo Giudice A, Marcantoni A, Vittone E, Carbone E, Lovisolo D. A diamondbased biosensor for the recording of neuronal activity. Biosensors \& Bioelectronics 2009 Mar;24(7):2046-2050.

[44] Yang WS, Hamers RJ. Fabrication and characterization of a biologically sensitive fieldeffect transistor using a nanocrystalline diamond thin film. Applied Physics Letters 2004 Oct;85(16):3626-3628.

[45] Jakubowski W, Bartosz G, Niedzielski P, Szymanski W, Walkowiak B. Nanocrystalline diamond surface is resistant to bacterial colonization. Diamond and Related Materials 2004 Oct;13(10):1761-1763.

[46] Papo MJ, Catledge SA, Vohra YK. Mechanical wear behavior of nanocrystalline and multilayer diamond coatings on temporomandibular joint implants. J Mater SciMater Med 2004 Jul;15(7):773-777.

[47] Nordsletten L, Hogasen AKM, Konttinen YT, Santavirta S, Aspenberg P, Aasen AO. Human monocytes stimulation by particles of hydroxyapatite, silicon carbide and diamond: In vitro studies of new prosthesis coatings. Biomaterials 1996 Aug;17(15):1521-1527.

[48] Aspenberg P, Anttila A, Konttinen YT, Lappalainen R, Goodman SB, Nordsletten L, et al. Benign response to particles of diamond and $\mathrm{SiC}$ : Bone chamber studies of new joint replacement coating materials in rabbits. Biomaterials 1996 Apr;17(8):807-812.

[49] Tang L, Tsai C, Gerberich WW, Kruckeberg L, Kania DR. Biocompatibility of ChemicalVapor-Deposited Diamond. Biomaterials 1995 Apr;16(6):483-488.

[50] Kulisch W, Popov C, Bliznakov S, Ceccone G, Gilliland D, Sirghi L, et al. Surface and bioproperties of nanocrystalline diamond/amorphous carbon nanocomposite films. Thin Solid Films 2007 Sep;515(23):8407-8411.

[51] Popov C, Kulisch W, Reithmaier JP, Dostalova T, Jelinek M, Anspach N, et al. Bioproperties of nanocrystalline diamond/amorphous carbon composite films. Diamond and Related Materials 2007 Apr-Jul;16(4-7):735-739.

[52] Rubio-Retama J, Hernando J, Lopez-Ruiz B, Hartl A, Steinmuller D, Stutzmann M, et al. Synthetic nanocrystalline diamond as a third-generation biosensor support. Langmuir 2006 Jun;22(13):5837-5842.

[53] Steinmuller-Nethl D, Kloss FR, Najam-U-Haq M, Rainer M, Larsson K, Linsmeier C, et al. Strong binding of bioactive BMP-2 to nanocrystalline diamond by physisorption. Biomaterials 2006 Sep;27(26):4547-4556.

[54] Haensel T, Uhlig J, Koch RJ, Ahmed SIU, Garrido JA, Steinmuller-Nethl D, et al. Influence of hydrogen on nanocrystalline diamond surfaces investigated with HREELS and XPS. Physica Status Solidi a-Applications and Materials Science 2009 Sep;206(9):2022-2027.

[55] Chong KF, Loh KP, Vedula SRK, Lim CT, Sternschulte H, Steinmuller D, et al. Cell adhesion properties on photochemically functionalized diamond. Langmuir 2007 May;23(10):5615-5621.

[56] Chen YC, Lee DC, Hsiao CY, Chung YF, Chen HC, Thomas JP, et al. The effect of ultrananocrystalline diamond films on the proliferation and differentiation of neural stem cells. Biomaterials 2009 Jul;30(20):3428-3435. 
[57] Yang L, Sheldon BW, Webster TJ. The impact of diamond nanocrystallinity on osteoblast functions. Biomaterials 2009 Jul;30(20):3458-3465.

[58] Clem WC, Chowdhury S, Catledge SA, Weimer JJ, Shaikh FM, Hennessy KM, et al. Mesenchymal stem cell interaction with ultra-smooth nanostructured diamond for wear-resistant orthopaedic implants. Biomaterials 2008 Aug-Sep;29(24-25):34613468 .

[59] Huang HJ, Chen M, Bruno P, Lam R, Robinson E, Gruen D, et al. Ultrananocrystalline Diamond Thin Films Functionalized with Therapeutically Active Collagen Networks. Journal of Physical Chemistry B 2009 Mar;113(10):2966-2971.

[60] Kalbacova M, Rezek B, Baresova V, Wolf-Brandstetter C, Kromka A. Nanoscale topography of nanocrystalline diamonds promotes differentiation of osteoblasts. Acta Biomaterialia 2009 Oct;5(8):3076-3085.

[61] Popov C, Bliznakov S, Boycheva S, Milinovik N, Apostolova MD, Anspach N, et al. Nanocrystalline diamond/amorphous carbon composite coatings for biomedical applications. Diamond and Related Materials 2008 Apr-May;17(4-5):882-887.

[62] Huang HJ, Pierstorff E, Osawa E, Ho D. Protein-mediated assembly of nanodiamond hydrogels into a biocompatible and biofunctional multilayer nanofilm. Acs Nano 2008 Feb;2(2):203-212.

[63] Jian W, Firestone MA, Auciello O, Carlisle JA. Surface functionalization of ultrananocrystalline diamond films by electrochemical reduction of aryldiazonium salts. Langmuir 2004 Dec;20(26):11450-11456.

[64] Wang J, Carlisle JA. Covalent immobilization of glucose oxidase on conducting ultrananocrystalline diamond thin films. Diamond and Related Materials 2006 FebMar;15(2-3):279-284.

[65] Williams DF. On the nature of biomaterials. Biomaterials 2009 Oct;30(30):5897-5909.

[66] Chen YC, Lee DC, Tsai TY, Hsiao CY, Liu JW, Kao CY, et al. Induction and regulation of differentiation in neural stem cells on ultra-nanocrystalline diamond films. Biomaterials 2010:In press.

[67] Kromka A, Grausova L, Bacakova L, Vacik J, Rezek B, Vanecek M, et al. Semiconducting to metallic-like boron doping of nanocrystalline diamond films and its effect on osteoblastic cells. Diamond and Related Materials Feb-Mar;19(23):190-195.

[68] Ariano P, Budnyk O, Dalmazzo S, Lovisolo D, Manfredotti C, Rivolo P, et al. On diamond surface properties and interactions with neurons. European Physical Journal E 2009 Oct;30(2):149-156.

[69] Shi B, Jin QL, Chen LH, Auciello O. Fundamentals of ultrananocrystalline diamond (UNCD) thin films as biomaterials for developmental biology: Embryonic fibroblasts growth on the surface of (UNCD) films. Diamond and Related Materials 2009 Feb-Mar;18(2-3):596-600.

[70] Bajaj P, Akin D, Gupta A, Sherman D, Shi B, Auciello O, et al. Ultrananocrystalline diamond film as an optimal cell interface for biomedical applications. Biomedical Microdevices 2007 Dec;9(6):787-794.

[71] Amaral M, Dias AG, Gomes PS, Lopes MA, Silva RF, Santos JD, et al. Nanocrystalline diamond: In vitro biocompatibility assessment by MG63 and human bone marrow cells cultures. Journal of Biomedical Materials Research Part A 2008 Oct;87A(1):9199. 
[72] Amaral M, Gomes PS, Lopes MA, Santos JD, Silva RF, Fernandes MH. Nanocrystalline diamond as a coating for joint implants: Cytotoxicity and biocompatibility assessment. Journal of Nanomaterials 2008:9.

[73] Kloss FR, Gassner R, Preiner J, Ebner A, Larsson K, Hachl O, et al. The role of oxygen termination of nanocrystalline diamond on immobilisation of BMP-2 and subsequent bone formation. Biomaterials 2008 Jun;29(16):2433-2442.

[74] Tate MC, Garcia AJ, Keselowsky BG, Schumm MA, Archer DR, LaPlaca MC. Specific beta(1) integrins mediate adhesion, migration, and differentiation of neural progenitors derived from the embryonic striatum. Molecular and Cellular Neuroscience 2004 Sep;27(1):22-31.

[75] Hynes RO, Yamada KM. Fibronectins - Multifunctional Modular Glycoproteins. Journal of Cell Biology 1982;95(2):369-377.

[76] Cui FZ, Li DJ. A review of investigations on biocompatibility of diamond-like carbon and carbon nitride films. Surface \& Coatings Technology 2000 Sep;131(1-3):481-487.

[77] Yang L, Sheldon BW, Webster TJ. Orthopedic nano diamond coatings: Control of surface properties and their impact on osteoblast adhesion and proliferation. Journal of Biomedical Materials Research Part A 2009 Nov;91A(2):548-556.

[78] Kalbacova M, Broz A, Babchenko O, Kromka A. Study on cellular adhesion of human osteoblasts on nano-structured diamond films. Physica Status Solidi B-Basic Solid State Physics 2009 Dec;246(11-12):2774-2777.

[79] Broz A, Baresova V, Kromka A, Rezek B, Kalbacova M. Strong influence of hierarchically structured diamond nanotopography on adhesion of human osteoblasts and mesenchymal cells. Phys Status Solidi A-Appl Mat 2009 Sep;206(9):2038-2041.

[80] Kalbacova M, Kalbac M, Dunsch L, Kromka A, Vanecek M, Rezek B, et al. The effect of SWCNT and nano-diamond films on human osteoblast cells. Physica Status Solidi B-Basic Solid State Physics 2007 Nov;244(11):4356-4359.

[81] Kalbacova M, Michalikova L, Baresova V, Kromka A, Rezek B, Kmoch S. Adhesion of osteoblasts on chemically patterned nanocrystalline diamonds. Physica Status Solidi B-Basic Solid State Physics 2008 Oct;245(10):2124-2127.

[82] Anselme K, Linez P, Bigerelle M, Le Maguer D, Le Maguer A, Hardouin P, et al. The relative influence of the topography and chemistry of TiAl6V4 surfaces on osteoblastic cell behaviour. Biomaterials 2000 Aug;21(15):1567-1577.

[83] Anselme K. Osteoblast adhesion on biomaterials. Biomaterials 2000 Apr;21(7):667-681.

[84] Thalhammer A, Edgington RJ, Cingolani LA, Schoepfer R, Jackman RB. The use of nanodiamond monolayer coatings to promote the formation of functional neuronal networks. Biomaterials Mar;31(8):2097-2104.

[85] Rezek B, Michalikova L, Ukraintsev E, Kromka A, Kalbacova M. Micro-Pattern Guided Adhesion of Osteoblasts on Diamond Surfaces. Sensors 2009 May;9(5):3549-3562.

[86] Ukraintsev E, Rezek B, Kromka A, Broz A, Kalbacova M. Long-term adsorption of fetal bovine serum on $\mathrm{H} / \mathrm{O}$-terminated diamond studied in situ by atomic force microscopy. Physica Status Solidi B-Basic Solid State Physics 2009 Dec;246(1112):2832-2835.

[87] Michalikova L, Rezek B, Kromka A, Kalbacova M. CVD diamond films with hydrophilic micro-patterns for self-organisation of human osteoblasts. Vacuum 2009 Aug;84(1):61-64. 
[88] Rezek B, Ukraintsev E, Michalikova L, Kromka A, Zemek J, Kalbacova M. Adsorption of fetal bovine serum on $\mathrm{H} / \mathrm{O}$-terminated diamond studied by atomic force microscopy. Diamond and Related Materials 2009 May-Aug;18(5-8):918-922.

[89] Rezek B, Ukraintsev E, Kromka A, Ledinsky M, Broz A, Noskova L, et al. Assembly of osteoblastic cell micro-arrays on diamond guided by protein pre-adsorption. Diamond and Related Materials Feb-Mar;19(2-3):153-157.

[90] Hamilton DW, Brunette DM. The effect of substratum topography on osteoblast adhesion mediated signal transduction and phosphorylation. Biomaterials 2007 Apr;28(10):1806-1819.

[91] Ivankovic-Dikic I, Gronroos E, Blaukat A, Barth BU, Dikic I. Pyk2 and FAK regulate neurite outgrowth induced by growth factors and integrins. Nature Cell Biology 2000 Sep;2(9):574-581.

[92] Mruthyunjaya S, Manchanda R, Godbole R, Pujari R, Shiras A, Shastry P. Laminin-1 induces neurite outgrowth in human mesenchymal stem cells in serum/differentiation factors-free conditions through activation of FAKMEK/ERK signaling pathways. Biochemical and Biophysical Research Communications Jan;391(1):43-48. 


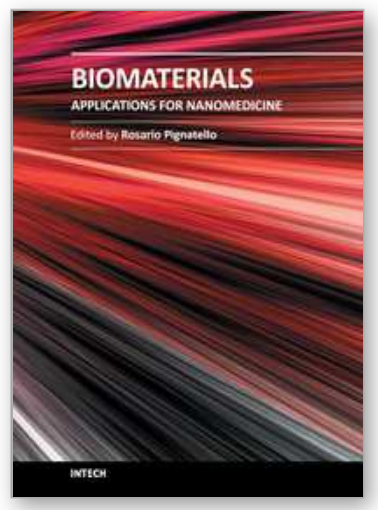

\author{
Biomaterials Applications for Nanomedicine \\ Edited by Prof. Rosario Pignatello
}

ISBN 978-953-307-661-4

Hard cover, 458 pages

Publisher InTech

Published online 16, November, 2011

Published in print edition November, 2011

These contribution books collect reviews and original articles from eminent experts working in the interdisciplinary arena of biomaterial development and use. From their direct and recent experience, the readers can achieve a wide vision on the new and ongoing potentialities of different synthetic and engineered biomaterials. Contributions were selected not based on a direct market or clinical interest, but on results coming from a very fundamental studies. This too will allow to gain a more general view of what and how the various biomaterials can do and work for, along with the methodologies necessary to design, develop and characterize them, without the restrictions necessary imposed by industrial or profit concerns. Biomaterial constructs and supramolecular assemblies have been studied, for example, as drug and protein carriers, tissue scaffolds, or to manage the interactions between artificial devices and the body. In this volume of the biomaterial series have been gathered in particular reviews and papers focusing on the application of new and known macromolecular compounds to nanotechnology and nanomedicine, along with their chemical and mechanical engineering aimed to fit specific biomedical purposes.

\title{
How to reference
}

In order to correctly reference this scholarly work, feel free to copy and paste the following:

Ying-Chieh Chen, Don-Ching Lee and Ing-Ming Chiu (2011). Nanocrystalline Diamond Films: Applications and Advances in Nanomedicine, Biomaterials Applications for Nanomedicine, Prof. Rosario Pignatello (Ed.), ISBN: 978-953-307-661-4, InTech, Available from: http://www.intechopen.com/books/biomaterials-applications-fornanomedicine/nanocrystalline-diamond-films-applications-and-advances-in-nanomedicine

\section{INTECH}

open science | open minds

\section{InTech Europe}

University Campus STeP Ri

Slavka Krautzeka 83/A

51000 Rijeka, Croatia

Phone: +385 (51) 770447

Fax: +385 (51) 686166

www.intechopen.com

\section{InTech China}

Unit 405, Office Block, Hotel Equatorial Shanghai

No.65, Yan An Road (West), Shanghai, 200040, China

中国上海市延安西路65号上海国际贵都大饭店办公楼 405 单元

Phone: +86-21-62489820

Fax: +86-21-62489821 
(C) 2011 The Author(s). Licensee IntechOpen. This is an open access article distributed under the terms of the Creative Commons Attribution 3.0 License, which permits unrestricted use, distribution, and reproduction in any medium, provided the original work is properly cited. 